\title{
Does the Urinary Calcium/Citrate Ratio Add to the Diagnostic Workup of Children at Risk of Kidney Stones? A Cross-Sectional Study
}

\author{
Misan Lee ${ }^{1}$ Carmen Inés Rodriguez Cuellar ${ }^{1,2,3}$ Ravneet Nagra ${ }^{1}$ Zhan Tao Peter Wang ${ }^{5}$ \\ Vipin Bhayana ${ }^{6}$ Guido Filler $1,4,6,7$
}

\footnotetext{
${ }^{1}$ Department of Paediatrics, Division of Paediatric Nephrology, Schulich School of Medicine and Dentistry, University of Western Ontario, London, Ontario, Canada

2 Departamento de Nefrología Pediátrica, Instituto Nacional de Pediatría, Mexico City, Mexico

${ }^{3}$ Universidad Nacional Autónoma de México, Mexico City, Mexico

${ }^{4}$ Lilibeth Caberto Kidney Clinical Research Unit, London Health

Sciences Centre, London Ontario, Canada

${ }^{5}$ Department of Surgery, Schulich School of Medicine and Dentistry, University of Western Ontario, London, Ontario, Canada

${ }^{6}$ Department of Pathology and Laboratory Medicine, Schulich School of Medicine and Dentistry, University of Western Ontario, London, Ontario, Canada

7 Department of Medicine, Division of Nephrology, Schulich School of Medicine and Dentistry, University of Western Ontario, London, Ontario, Canada
}

J Child Sci 2019;9:e1-e6.

\begin{abstract}
Address for correspondence Guido Filler, MD, PhD, FRCPC, Medicine and Pathology and Laboratory Medicine, Children's Hospital, London Health Sciences Centre, University of Western Ontario, 800 Commissioners Road East, Rm B1-135, London ON, Canada, N6A 5W9 (e-mail: guido.filler@lhsc.on.ca).
\end{abstract}

\begin{abstract}
Keywords

- urinary calcium

- urinary citrate

- urinary creatinine

- urinary oxalate

- urolithiasis

The purpose of the study was to evaluate urinary citrate/creatinine $\left(U_{\mathrm{C}_{\mathrm{i}}} / \mathrm{U}_{\mathrm{Cr}_{\mathrm{r}}}\right)$ and urinary calcium/citrate $\left(\mathrm{U}_{\mathrm{Ca}} / \mathrm{U}_{\mathrm{Ci}}\right)$ ratios for distinguishing stone formers (SF) from nonstone formers (NSF) in an at-risk population. This was a retrospective study that included all pediatric patients who underwent urinary citrate testing from April 2017 to March 2018. The urinary levels of citrate, calcium, sodium, potassium, creatinine, oxalate, urate, $\mathrm{pH}$, and specific gravity (SG) were measured in our clinical laboratory. Diagnosis of kidney stones was obtained through chart review.

A total of 97 patients were included (46 NSF and $51 \mathrm{SF}$ ). The $U_{\mathrm{C}_{\mathrm{i}}} / \mathrm{U}_{\mathrm{Cr}}$ ratio was not significantly different between NSF and SF. Median $\mathrm{U}_{\mathrm{Ca}} / \mathrm{U}_{\mathrm{Cr}}$ ratio was higher in SF $(0.67)$ compared with NSF $(0.21, p<0.0001)$. The median ratio of $\mathrm{U}_{\mathrm{Ca}} / \mathrm{U}_{\mathrm{Ci}}$ was also higher in SF (1.30) than in NSF $(0.65, p=0.001)$. Oxalate, urate, $\mathrm{pH}, \mathrm{SG}$, and urinary sodium/ potassium ratio did not differentiate between the SF and NSF. Positive correlation was seen between $U_{\mathrm{Ca}} / \mathrm{U}_{\mathrm{Cr}}$ and urinary sodium/creatinine $\mathrm{U}_{\mathrm{Na}} / \mathrm{U}_{\mathrm{Cr}}(p<0.0001)$, as well as between $\mathrm{U}_{\mathrm{Ca}} / \mathrm{U}_{\mathrm{Cr}}$ and $\mathrm{U}_{\mathrm{Ci}} / \mathrm{U}_{\mathrm{Cr}}(p<0.0001)$.

The study has demonstrated significantly higher $\mathrm{U}_{\mathrm{Ca}} / \mathrm{U}_{\mathrm{Ci}}$ and $\mathrm{U}_{\mathrm{Ca}} / \mathrm{U}_{\mathrm{Cr}}$ in $\mathrm{SF}$ compared with NSF, while the use of urinary oxalate, urate, $\mathrm{pH}$, and SG did not differentiate between SF from NSF. We also confirmed a positive correlation between $U_{N a} / U_{C r}$ and $\mathrm{U}_{\mathrm{Ca}} / \mathrm{U}_{\mathrm{Cr}}$. While the utility of $\mathrm{U}_{\mathrm{Ca}} / \mathrm{U}_{\mathrm{Cr}}$ is well established, our data suggest that $\mathrm{U}_{\mathrm{Ca}} / \mathrm{U}_{\mathrm{Ci}}$ rather than $\mathrm{U}_{\mathrm{Ci}} / \mathrm{U}_{\mathrm{Cr}}$ may be more predictive in the clinical setting when evaluating for nephrolithiasis.
\end{abstract}

received

August 24, 2018 accepted after revision January 3, 2019
DOI https://doi.org/

10.1055/s-0039-1677818. ISSN 2474-5871.
Copyright $\odot 2019$ Georg Thieme Verlag License terms

KG Stuttgart · New York
(1) (1) 


\section{Introduction}

The prevalence of urolithiasis is increasing around the world, especially among children. ${ }^{1}$ Citrate can inhibit stone formation by forming a chelate complex with calcium in the urine, thereby inhibiting spontaneous nucleation and preventing the growth of crystals. ${ }^{2}$ Hypocitraturia is a well-recognized risk factor for the development of kidney stones, ${ }^{2}$ and it is identified as a metabolic abnormality in 20 to $60 \%$ of adult stone formers (SF). ${ }^{2,3}$ In children, the demographics of nephrolithiasis have been changing ${ }^{1}$ and hypocitraturia has now emerged as the most prevalent reason for nephrolithiasis in children. ${ }^{4,5}$ Contributing to the development of hypocitraturia are distal renal tubular acidosis, hypokalemia, bowel dysfunction, and a high-protein and low-alkali diet. ${ }^{2}$

The gold standard for the diagnosis of hypocitraturia is a 24-hour urine collection and it is defined as urinary citrate excretion $<320 \mathrm{mg}(1.67 \mathrm{mmol})$ per 24 hours for adults. ${ }^{6}$ In children, 24-hour urine collections are notoriously unreliable. ${ }^{7}$ Although age-dependent reference intervals for urinary citrate to creatinine ratios $\left(\mathrm{U}_{\mathrm{Ci}} / \mathrm{U}_{\mathrm{Cr}}\right)$ have been established, ${ }^{8}$ our own experience of the diagnostic yield of hypocitraturia to differentiate SF from non-SF (NSF) has been low. Höbarth and Hofbauer also suggested a limited value for $\mathrm{U}_{\mathrm{Ci}} / \mathrm{U}_{\mathrm{Cr} \cdot}{ }^{9}$

Recent studies have suggested that urinary calcium to citrate ratio $\left(\mathrm{U}_{\mathrm{Ca}} / \mathrm{U}_{\mathrm{Ci}}\right)$ would be a superior marker to identify those at risk of urolithiasis. ${ }^{10-13}$ Sikora et al. ${ }^{14}$ compared the yield of $U_{C a} / U_{C i}$ as compared with hypercalciuria and hypocitraturia for the identification of SF in children and found $\mathrm{U}_{\mathrm{Ci}} / \mathrm{U}_{\mathrm{Cr}}$ to be superior; however, no precise cutoffs were determined. As the topic is understudied, we performed a retrospective study to evaluate the utility of $\mathrm{U}_{\mathrm{Ca}} / \mathrm{U}_{\mathrm{Ci}}$ to identify stone formation in a pediatric population. We also wanted to determine the diagnostic cutoff values including state-of-the-art Youden's index calculation for $\mathrm{U}_{\mathrm{Ci}} / \mathrm{U}_{\mathrm{Cr}}$, to determine the best reporting of risk factors for children with nephrolithiasis. We hypothesized that the $\mathrm{U}_{\mathrm{Ca}} / \mathrm{U}_{\mathrm{Ci}}$ in a spot urine would differentiate between SF and NSF patients.

\section{Materials and Methods}

\section{Study Design}

This retrospective cohort study adhered to the Declaration of Helsinki and was approved without the need to obtain written informed consents by the Research Ethics Board of the University of Western Ontario (REB no.109434). The study was conducted at the Children's Hospital of London Health Sciences Centre (LHSC); a teaching hospital for the University of Western Ontario.

The LHSC is a tertiary referral center with a catchment area of 629,000 children and youths in Southern and Northwestern Ontario in Canada. The population is predominantly Caucasian, with a $15 \%$ Middle Eastern minority, $<5 \%$ indigenous population, and a very small African-American population. All patients from the pediatric nephrology clinic who had at least one urinary citrate ordered from April 2017 to March 2018 were eligible for the study. Patients were classified as either having confirmed nephro- or urolithiasis (SF) or not (NSF) based on the presence of urolithiasis on ultrasound or other imaging modalities (computed tomography and Xray studies); and stone analysis for those who spontaneously passed stones prior to imaging. If more than one measurement was available per patient, we only used the earliest measurement within the study period to reduce the impact of any intervention such as changes in lifestyle.

\section{Experimental Methods}

Patients were identified through the Laboratory Information System at LHSC. The spot urinary levels of citrate, calcium, sodium, potassium, creatinine, oxalate, urate, $\mathrm{pH}$, specific gravity, diagnoses of stone formation, and ultrasound findings were obtained through review of physical charts and electronic medical records. Methods for the urinary biomarkers have been previously published. ${ }^{15}$ Values were reported in standard international units. Urinary citrate was measured enzymatically using a BEN-Biochemical Enterprise (Milano, Italy) diagnostic kit.

\section{Statistical Methods}

Data analysis was performed using GraphPad Prism 5 for Mac OS X (GraphPad Inc., San Diego, California, United States, version 5.0f). Normal distribution was tested using the D'Agostino \& Pearson omnibus normality test. Normally distributed parameters were analyzed using parametric tools; otherwise, nonparametric tools were used to report median, and 25th and 75th percentiles. For correlation analysis, we used the Pearson correlation coefficient. The diagnostic performance of all urinary parameters and urinary ratios was assessed using receiver-operated-characteristics (ROC) plots. To compare ROC curves, we used the method proposed by Hanley. ${ }^{16}$ Youden's index was used to calculate the optimal cutoff value for the identification of stone formation $\left(\mathrm{U}_{\mathrm{Ca}} / \mathrm{U}_{\mathrm{Ci}}\right) .{ }^{17}$ No adjustments were made for missing values. The missing data values were predominantly $\mathrm{U}_{\mathrm{Na}}, \mathrm{U}_{\mathrm{K}}$, and $\mathrm{U}_{\text {Oxalate }}$.

\section{Theory/Calculation}

Youden's statistic, Gini index, chi-square statistic, relative risk, and kappa statistic all theoretically recover a true threshold. ${ }^{18}$ While chi-square statistic and Gini index may have the smallest bias, Youden's statistics are deemed best when the probability is larger. ${ }^{18}$ Therefore, Youden's index was used in this study.

\section{Results}

A total of 97 patients were reviewed with 46 NSF and 51 SF patients. Patient characteristics are provided in - Table 1. The indications for spot urine testing in our study population were as follows: all patients in the SF group had nephrolithiasis, 11 (25\%) of the NSF group had microscopic hematuria, 8 (17\%) had glomerulonephritis, $7(15 \%)$ had a tubulopathy, $7(15 \%)$ had congenital anomalies of the kidneys and urinary tract (CAKUT), $5(11 \%)$ had urinary tract infections, $2(4 \%)$ had metabolic syndrome, and 6(13\%) had miscellaneous diagnoses (dysfunctional voiding, primary enuresis, cystic fibrosis, neuroblastoma, chromium intoxication, and failure to thrive). The reasons for 
Table 1 Patients' characteristics and comparison of parameters

\begin{tabular}{|c|c|c|c|c|}
\hline Group & SF & NSF & Comparison & Test \\
\hline Number of patients & 51 & 46 & & \\
\hline Age (y) (median, IQR) & $8(3,15)$ & $10(6.8,15)$ & 0.1755 & Mann-Whitney $U$ test \\
\hline Female (\%) & $19(37.3 \%)$ & $22(47.8 \%)$ & 0.3074 & Fisher's exact test \\
\hline Urinary citrate (mmol/L) (median, IQR) & $1.55(0.95,2.32)$ & $1.675(0.79,3.13)$ & 0.7743 & Mann-Whitney $U$ test \\
\hline Urinary calcium (mmol/L) (median, IQR) & $1.87(1.21,4.29)$ & $1.0(0.26,2.3)$ & 0.0021 & Mann-Whitney $U$ test \\
\hline Urinary sodium (mmol/L) (median, IQR) & $77(30,121)$ & $107(48,154)$ & 0.0963 & Mann-Whitney $U$ test \\
\hline Urinary potassium (mmol/L), (median, IQWR) & $42(28,101)$ & $48(19,80)$ & 0.9895 & Mann-Whitney $U$ test \\
\hline Urinary creatinine $(\mu \mathrm{mol} / \mathrm{L})$, (median, IQR) & $3.4(1.5,6.8)$ & $4.6(1.9,9.0)$ & 0.3878 & Mann-Whitney $U$ test \\
\hline Urinary oxalate ( $\mu \mathrm{mol} / \mathrm{L}),($ median, IQR) & $189(111,291)$ & $134(38,290)$ & 0.1438 & Mann-Whitney $U$ test \\
\hline Urinary urate $(\mu \mathrm{mol} / \mathrm{L}),($ median, IQR) & $1.9(1,5.7)$ & $2.3(1,12)$ & 0.2544 & Mann-Whitney $U$ test \\
\hline Urinary $\mathrm{pH}($ mean $\pm \mathrm{SD})$ & $6.6 \pm 0.91$ & $6.5 \pm 0.98$ & 0.7366 & Student's t-test \\
\hline Urinary-specific gravity (median and IQR) & $\begin{array}{l}1.010 \\
(1.005,1.020)\end{array}$ & $\begin{array}{l}1.015 \\
(1.005,1.020)\end{array}$ & 0.1842 & Mann-Whitney $U$ test \\
\hline $\begin{array}{l}\text { Urinary citrate/creatinine } \\
\text { (mmol/mmol) (median, IQR) }\end{array}$ & $0.48(0.21,0.90)$ & $0.38(0.21,0.86)$ & 0.8784 & Mann-Whitney $U$ test \\
\hline $\begin{array}{l}\text { Urinary calcium/creatinine } \\
\text { (mmol/mmol) (median, IQR) }\end{array}$ & $0.67(0.31,1.37)$ & $0.24(0.11,0.73)$ & 0.0029 & Mann-Whitney $U$ test \\
\hline $\begin{array}{l}\text { Urinary calcium/citrate } \\
(\mathrm{mmol} / \mathrm{mmol}) \text { (median, IQR) }\end{array}$ & $1.30(0.73,2.78)$ & $0.68(0.29,1.83)$ & 0.0114 & Mann-Whitney $U$ test \\
\hline $\begin{array}{l}\text { Urinary sodium/potassium } \\
(\mathrm{mmol} / \mathrm{mmol})(\text { mean } \pm \mathrm{SD})\end{array}$ & $2.08 \pm 1.92$ & $2.50 \pm 1.36$ & 0.3185 & Student's t-test \\
\hline
\end{tabular}

Abbreviations: IQR, interquartile range; NSF, non-stone former; SD, standard deviation.

Glossary for Table 1: IQR (25th and 75th percentiles).

Note: Statistically significant differences were bolded. The comparison column represents the $p$-value, and in the test column, the test that was used is listed (based on the distribution and data type).

ordering urinary citrate in the 35 patients who did not have microscopic hematuria were not stated. SF did not differ from NSF regarding age, gender, urinary citrate, urinary sodium, urinary potassium, urinary creatinine, urinary oxalate, urinary urate, urinary $\mathrm{pH}$, urinary specific gravity, $\mathrm{U}_{\mathrm{Ci}} / \mathrm{U}_{\mathrm{Cr}}$, and urinary sodium/potassium ratio $\left(\mathrm{U}_{\mathrm{Na}} / \mathrm{U}_{\mathrm{Pa})}\right.$ ( - Table 1). Statistically significant differences only existed for the $U_{\mathrm{Ca}} / \mathrm{U}_{\mathrm{Cr}}$, urinary $\mathrm{U}_{\mathrm{Ca}} / \mathrm{U}_{\mathrm{Ci}}$, and urinary calcium concentration.

In our population, a diagnosis of hypocitraturia was not predictive of stone formation ( 4 of the NSF vs. 7 of the SF had hypocitraturia, $p=0.5283$ ). We then examined correlations previously tested in the literature. There was a statistically significant positive correlation between the $\mathrm{U}_{\mathrm{Ca}} / \mathrm{U}_{\mathrm{Cr}}$ and urinary sodium/creatinine ratio $\left(\mathrm{U}_{\mathrm{Na}} / \mathrm{U}_{\mathrm{Cr}}\right.$ ) (Pearson $\left.r^{2}=0.5099, p<0.0001\right)$. In contrast to the expected negative correlation between the $\mathrm{U}_{\mathrm{Ca}} / \mathrm{U}_{\mathrm{Cr}}$ and the urinary potassium/creatinine ratio $\left(\mathrm{U}_{\mathrm{Pa}} / \mathrm{U}_{\mathrm{Ci}}\right)$, a weak positive correlation (Pearson $r^{2}=0.126, p=0.0036$ ) was demonstrated. $\mathrm{U}_{\mathrm{Ca}} / \mathrm{U}_{\mathrm{Cr}}$ also correlated positively but weakly with $\mathrm{U}_{\mathrm{Ci}} / \mathrm{U}_{\mathrm{Cr}}$ (Pearson $\left.r^{2}=0.1180, p=0.0007\right)$. In addition, $\mathrm{U}_{\mathrm{Ca}} / \mathrm{U}_{\mathrm{Cr}}$ correlated positively with $\mathrm{U}_{\mathrm{Ca}} / \mathrm{U}_{\mathrm{Ci}}$ (Pearson $r^{2}=0.5511, p<0.0001$ ).

Furthermore, we determined the ROC area of the SF versus NSF group. Useful discrimination between SF and NSF existed for $\mathrm{U}_{\mathrm{Ca}} / \mathrm{U}_{\mathrm{Cr}}$ (ROC area $0.7361 \pm 0.05109$ with a $95 \%$ confidence interval between 0.636 and $0.836, p<0.0001$ ) and for $\mathrm{U}_{\mathrm{Ca}} / \mathrm{U}_{\mathrm{Ci}}$ (ROC area $0.6965 \pm 0.05418$ with a $95 \%$ confidence interval between 0.590 and $0.803, p=0.00098$ ). The ROC areas for $\mathrm{U}_{\mathrm{Ca}} /$ $\mathrm{U}_{\mathrm{Cr}}$ and $\mathrm{U}_{\mathrm{Ca}} / \mathrm{U}_{\mathrm{Ci}}$ did not differ $(p=0.5029)$. The $\mathrm{U}_{\mathrm{Ci}} / \mathrm{U}_{\mathrm{Cr}}$ ROC area was $0.5603 \pm 0.05942$, with a $95 \%$ confidence interval between 0.444 and $0.677, p=0.3112$.

Youden's Index derived from the ROC curves showed that a $\mathrm{U}_{\mathrm{Ca}} / \mathrm{U}_{\mathrm{Ci}}$ ratio $>0.68 \mathrm{mmol} / \mathrm{mmol}$ was associated with stone formation (-Fig. 1). When differentiating SF and NSF, 10 (20\%) SF patients had an $\mathrm{U}_{\mathrm{Ca}} / \mathrm{U}_{\mathrm{Ci}}$ ratio $<0.68$ compared with 27 (58\%) NSF, while $39(80 \%)$ SF had $U_{\mathrm{Ca}} / \mathrm{U}_{\mathrm{Ci}}$ ratio $>0.68$ as compared with 19 (42\%) NSF patients $(p<0.001)$. The diagnostic sensitivity at this cutoff was $80 \%$ and the specificity was $59 \%$. When repeating this analysis for $\mathrm{U}_{\mathrm{Ca}} / \mathrm{U}_{\mathrm{Cr}}, 24$ (47\%) SF patients had an $\mathrm{U}_{\mathrm{Ca}} / \mathrm{U}_{\mathrm{Cr}}$ ratio $<0.60$ as compared with 36 (78\%) NSF, while 27 (53\%) SF had $\mathrm{U}_{\mathrm{Ca}} / \mathrm{U}_{\mathrm{Cr}}$ ratio $>0.60$ as compared with 10 (22\%) NSF patients $(p=0.0018)$. The patients were not the same. Only 10 patients had both hypercalciuria and unfavorably high $\mathrm{U}_{\mathrm{Ca}} / \mathrm{U}_{\mathrm{Cr}}$ (-Fig. 2). As can be seen from - Fig. 2, only 10 patients had both an elevated $\mathrm{U}_{\mathrm{Ca}} / \mathrm{U}_{\mathrm{Ci}}$ and $\mathrm{U}_{\mathrm{Ca}} / \mathrm{U}_{\mathrm{Cr}}$. Both ratios differentiate between NSF and $\mathrm{SF}$, with $\mathrm{U}_{\mathrm{Ca}} / \mathrm{U}_{\mathrm{Ci}}$ actually providing a stronger discrimination, however, the two ratios identified different populations.

\section{Discussion}

The role of the pediatric nephrologist is to identify and diagnose modifiable causes of nephro- or urolithiasis. While 


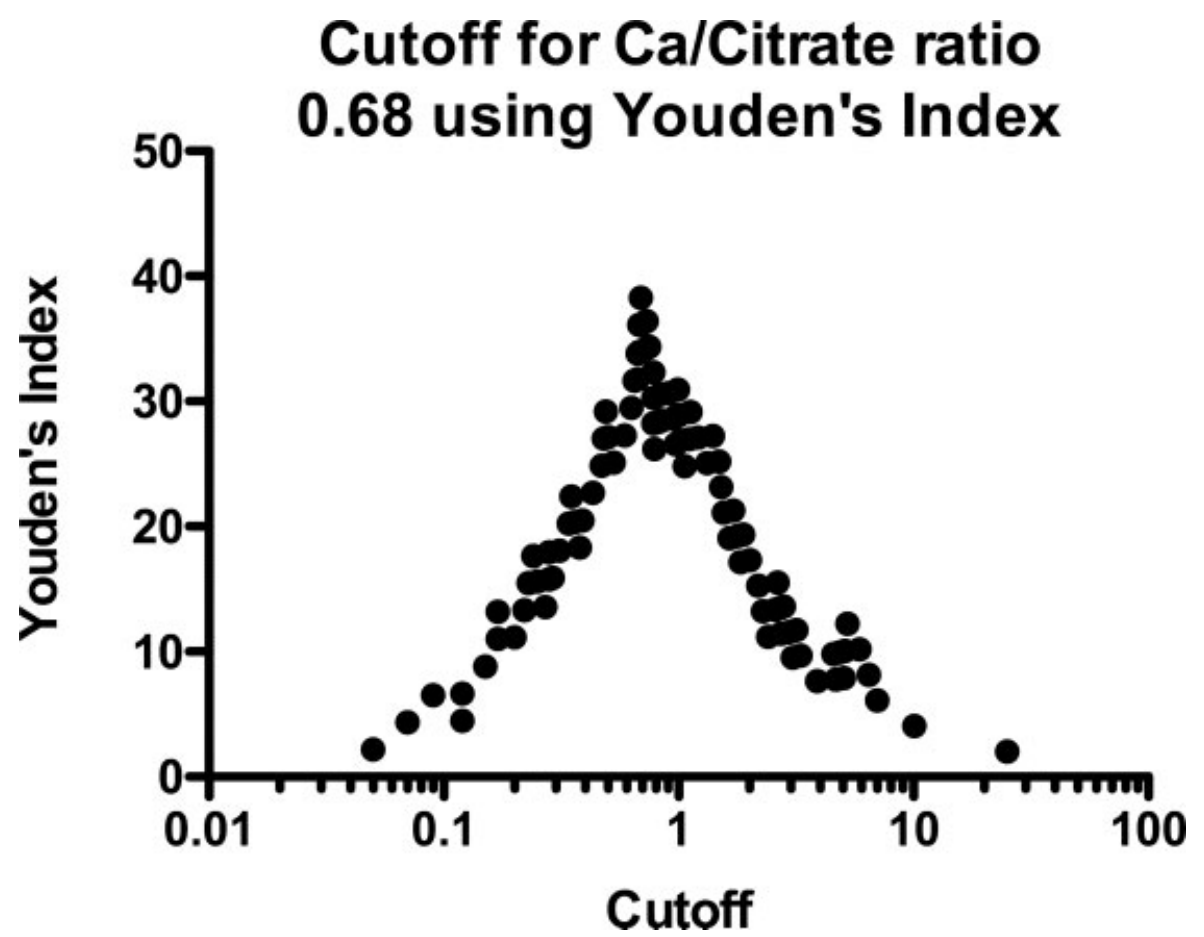

Fig. 1 Cutoff for urinary calcium/citrate $\left(U_{C a} / U_{C i}\right)$ using Youden's index derived from the $U_{C a} / U_{C i}$ ROC curve. ROC, receiver operated characteristics.

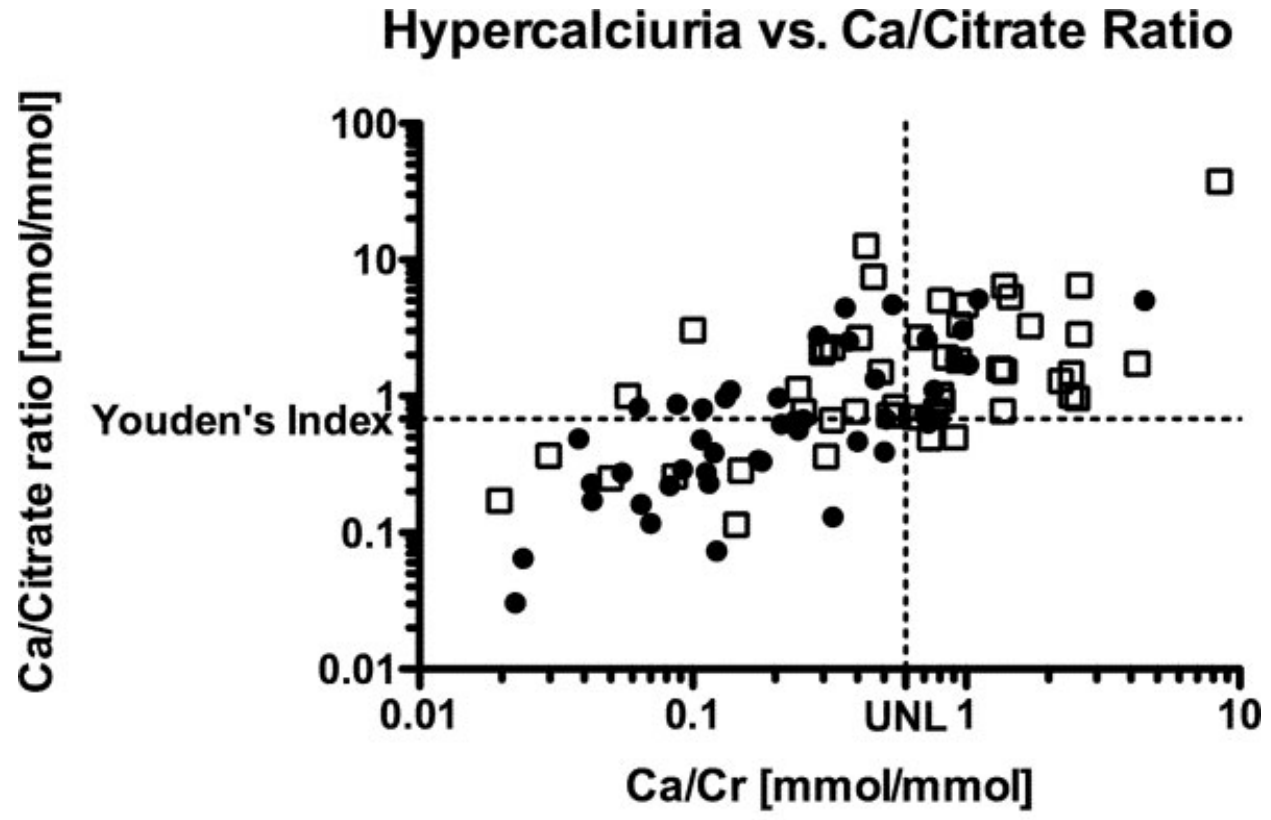

- SF Ca/Citrate

NSF Ca/Citrate

Fig. 2 Comparison of patients' urinary calcium/citrate $\left(U_{C_{a}} / U_{C_{i}}\right)$ and calcium/creatinine $\left(U_{C_{a}} / U_{C r}\right)$. Stone formers are marked in black circles, whereas non-stone formers are marked in open squares. As can be seen only 10 patients had both an elevated $U_{\mathrm{Ca}} / U_{\mathrm{Ci}}$ and $U_{\mathrm{Ca}} / U_{\mathrm{Cr}}$. Both ratios differentiate between NSF and SF, but they identify differing populations. NSF, non-stone formers; SF, stone formers.

many factors contribute to nephro- or urolithiasis, the current recommended approach is the use of $\mathrm{U}_{\mathrm{Ca}} / \mathrm{U}_{\mathrm{Cr}}$ and $\mathrm{U}_{\mathrm{Ci}} / \mathrm{U}_{\mathrm{Cr}}$ for distinguishing SF from NSF. In this study, we found a low diagnostic yield for $\mathrm{U}_{\mathrm{Ci}} / \mathrm{U}_{\mathrm{Cr}}$, similar to Höbarth and Hofbauer. $^{9}$ This low yield could be associated with the complexities of lithogenesis. The identification of a single metabolic factor may provide insufficient information for diagnosis, therapeutic, and preventive measures. ${ }^{14}$ In contrast, $\mathrm{U}_{\mathrm{Ca}} / \mathrm{U}_{\mathrm{Cr}}$ and $\mathrm{U}_{\mathrm{Ca}} / \mathrm{U}_{\mathrm{Ci}}$ had a reasonable diagnostic performance as shown in the ROC areas. However, both ratios 
identified different patient cohorts, and only 10 of the SF had both elevated $\mathrm{U}_{\mathrm{Ca}} / \mathrm{U}_{\mathrm{Cr}}$ and $\mathrm{U}_{\mathrm{Ca}} / \mathrm{U}_{\mathrm{Ci}}$.

The present study suggests that elevated $\mathrm{U}_{\mathrm{Ca}} / \mathrm{U}_{\mathrm{Ci}}$ is an independent risk factor for stone formation, rather than hypocitraturia. In other words, what promotes stone formation may not be the absolute citrate deficiency, but rather insufficient citrate for a given calcium concentration. Parks and $\mathrm{Coe}^{19}$ found in adults with urolithiasis a higher level of urine calcium for any given level of urine citrate, while Cupisti et al suggested that this relation was higher in recurrent $\mathrm{SF}^{20}$

After establishing Youden's index for the cutoff point and p-values, $\mathrm{U}_{\mathrm{Ca}} / \mathrm{U}_{\mathrm{Ci}}$ was more predictive of stone formation than $\mathrm{U}_{\mathrm{Ca}} / \mathrm{U}_{\mathrm{Cr}}$. However, populations with hypercalciuria and hypocitraturia correspond with different etiologies for lithogenesis, suggesting that both ratios may be useful biomarkers and may both be needed for assessing overall patient risk.

We did not assess whether potassium citrate therapy versus hydrochlorothiazide would be better therapies. However, hydrochlorothiazide treatment tends to reduce serum potassium, increase uric acid levels, and lower urinary citrate excretion. ${ }^{21}$ These side effects may actually contravene the urinary calcium-lowering effect, whereas the adverse effects of potassium citrate are limited to abdominal distension, diarrhea, nausea, and abdominal pain. ${ }^{22}$ Supplementation of citrate may be safer than the use of hydrochlorothiazide for decreasing the risk of nephrolithiasis in hypercalciuria.

In Canada, treatment with hydrochlorothiazide is most commonly prescribed for hypercalciuria because potassium citrate is not covered. Others have used lemon juice as an alternative to potassium citrate. Kang et $\mathrm{al}^{23}$ found an increase in urinary citrate levels and a decrease in the stone formation rates in 11 adults after 44 months of lemonade therapy consisted of $120 \mathrm{~mL}$ concentrated lemon juice $(5.9 \mathrm{~g}$ citric acid) mixed with $2 \mathrm{~L}$ of water throughout each day. ${ }^{23}$ Penniston et $\mathrm{al}^{24}$ compared grape, orange, lime, and lemon juice both from fresh fruit and from juice concentrates and found that lime and lemon provide more citric acid per liter than others. ${ }^{24}$

Several papers have identified that $\mathrm{U}_{\mathrm{Ca}} / \mathrm{U}_{\mathrm{Ci}}$ may be preferable for the identification of SF. ${ }^{10-13,25}$ Using Youden's index, a cutoff of $\mathrm{U}_{\mathrm{Ca}} / \mathrm{U}_{\mathrm{Ci}}$ ratio $>0.68 \mathrm{mmol} / \mathrm{mmol}$ was determined for the identification of SF. Arrabal-Polo et $\mathrm{al}^{12}$ suggested a cutoff of $0.25 \mathrm{mg} / \mathrm{mg}$ (which would be $1.2 \mathrm{mmol} /$ mmol) to identify recurrent SF; however, the authors did not use a standardized method for deriving the cutoff. The only other study on children by Turudic et al suggests that a $U_{\mathrm{Ca}} /$ $\mathrm{U}_{\mathrm{Ci}}$ ratio below $0.61 \mathrm{mmol} / \mathrm{mmol}$ would identify healthy children, ${ }^{26}$ but again without any analysis beyond a subjective ROC curve inspection. Our cutoff value of $0.68 \mathrm{mmol} /$ mmol is very similar to that of Turudic et al, albeit determined by more statistically sound methods.

The study has several limitations, including the retrospective nature of the study, the number of patients and a few (maximum 8 per parameter) missing urine electrolytes (mostly potassium and sodium owing to the retrospective nature and lack of a prospective stone workup protocol).
Also, there may have been a selection bias because only pediatric nephrology patients were recruited, rather than the general population. We did not utilize 24-hour urine collections even though these may be more accurate; however, they are notoriously unreliable in children. ${ }^{27}$ Additionally in the NSF we did not control for pre-existing conditions that may have an increased risk for kidney stones such as comorbidities like inflammatory bowel disease, need for tube feeds, or cystic fibrosis. One patient in the control group had cystic fibrosis, but no hematuria. Furthermore, while only the earliest measurement in a time period was used, not all patients actually had measurements preintervention. We also realize that kidney stones in low-income countries may be more commonly formed by uric acid or ammonium. This could decrease the utility of $\mathrm{U}_{\mathrm{Ca}} / \mathrm{U}_{\mathrm{Ci}}$ to identify SF in those countries. ${ }^{28}$ Nonetheless, the previously proposed cutoffs of around $0.68 \mathrm{mmol} / \mathrm{mmol}$ have been solidified. As the sensitivity at this cutoff was $80 \%$ and the specificity was $59 \%$, future prospective studies should validate this cutoff.

\section{Conclusion}

This study adds to the growing body of literature supporting both the reporting and use of $\mathrm{U}_{\mathrm{Ca}} / \mathrm{U}_{\mathrm{Ci}}$ instead of $\mathrm{U}_{\mathrm{Ci}} / \mathrm{U}_{\mathrm{Cr}}$ to identify pediatric $\mathrm{SF}$ and through an appropriate statistical method propose a cutoff of $0.68 \mathrm{mmol} / \mathrm{mmol}$. Given the results of our analysis, we propose for pediatric patients with nephro- or urolithiasis that an initial urinary workup includes urinary creatinine, urinary calcium, and urinary citrate, in addition to the inexpensive urinary sodium and potassium. The authors further propose the use of $U_{\mathrm{Ca}} / \mathrm{U}_{\mathrm{Ci}}$ to identify patients at risk of urolithiasis and possibly for initiation of treatment with potassium citrate or even lemon juice. Future prospective studies would be important to validate the findings.

\section{Authors' Contributions}

GF and ML articulated the conceptual framework for this study and obtained ethics approval. VB retrieved the urinary citrate concentrations from the laboratory information system and linked all available data. ML pulled all the charts and performed the data entry. GF developed the analytical approach and GF, ML, CIRC, and RN analyzed the data. GF and CIRC drafted the manuscript. RN, PW, and VB contributed to the interpretation of data, added intellectual content during manuscript preparation, and provided valuable feedback on various aspects of the manuscript. All authors read and approved the final manuscript.

\section{Conflict of Interest}

None declared.

\section{Acknowledgments}

We express our gratitude for the excellent laboratory staff and the high routine clinical biochemistry testing at LHSC. The authors have no financial relationships relevant to this article to disclose. 


\section{References}

1 Sharma AP, Filler G. Epidemiology of pediatric urolithiasis. Indian J Urol 2010;26(04):516-522

2 Zuckerman JM, Assimos DG. Hypocitraturia: pathophysiology and medical management. Rev Urol 2009;11(03):134-144

3 Caudarella R, Vescini F. Urinary citrate and renal stone disease: the preventive role of alkali citrate treatment. Arch Ital Urol Androl 2009;81(03):182-187

4 Kovacevic L, Wolfe-Christensen C, Edwards L, Sadaps M, Lakshmanan Y. From hypercalciuria to hypocitraturia-a shifting trend in pediatric urolithiasis? J Urol 2012;188(4, Suppl):1623-1627

5 Lee ST, Cho H. Metabolic features and renal outcomes of urolithiasis in children. Ren Fail 2016;38(06):927-932

6 Chow K, Dixon J, Gilpin S, Kavanagh JP, Rao PN. Citrate inhibits growth of residual fragments in an in vitro model of calcium oxalate renal stones. Kidney Int 2004;65(05):1724-1730

7 Yang EM, Yoon BA, Kim SW, Kim CJ. Clinical utility of spot urine protein-to-creatinine ratio modified by estimated daily creatinine excretion in children. Pediatr Nephrol 2017;32(06):1045-1051

8 Kirejczyk JK, Porowski T, Konstantynowicz J, et al. Urinary citrate excretion in healthy children depends on age and gender. Pediatr Nephrol 2014;29(09):1575-1582

9 Höbarth K, Hofbauer J. Value of routine citrate analysis and calcium/ citrate ratio in calcium urolithiasis. Eur Urol 1991;19(02):165-168

10 Srivastava T, Winston MJ, Auron A, Alon US. Urine calcium/citrate ratio in children with hypercalciuric stones. Pediatr Res 2009;66 (01):85-90

11 DeFoor W, Jackson E, Schulte M, Alam Z, Asplin J. Calcium-tocitrate ratio distinguishes solitary and recurrent urinary stone forming children. J Urol 2017;198(02):416-421

12 Arrabal-Polo MA, Arias-Santiago S, Girón-Prieto MS, et al. Hypercalciuria, hyperoxaluria, and hypocitraturia screening from random urine samples in patients with calcium lithiasis. Urol Res 2012;40(05):511-515

13 Smith D, Laing C. Importance of citrate and the calcium: citrate ratio in patients with calcium renal lithiasis and severe lithogenesis. BJU Int 2013;111(04):529-530

14 Sikora P, Zajaczkowska M, Hoppe B. Assessment of crystallization risk formulas in pediatric calcium stone-formers. Pediatr Nephrol 2009;24(10):1997-2003
15 Huynh M, Clark R, Li J, Filler G, Dave S. A case control analysis investigating risk factors and outcomes for nephrocalcinosis and renal calculi in neonates. J Pediatr Urol 2017;13(04):356.e1-356.e5

16 Hanley JA, McNeil BJ. A method of comparing the areas under receiver operating characteristic curves derived from the same cases. Radiology 1983;148(03):839-843

17 Hughes G. Youden's index and the weight of evidence. Methods Inf Med 2015;54(02):198-199

18 Prince Nelson SL, Ramakrishnan V, Nietert PJ, Kamen DL, Ramos PS, Wolf BJ. An evaluation of common methods for dichotomization of continuous variables to discriminate disease status. Commun Stat Theory Methods 2017;46(21):10823-10834

19 Parks JH, Coe FL. A urinary calcium-citrate index for the evaluation of nephrolithiasis. Kidney Int 1986;30(01):85-90

20 Cupisti A, Morelli E, Lupetti S, Meola M, Barsotti G. Low urine citrate excretion as main risk factor for recurrent calcium oxalate nephrolithiasis in males. Nephron 1992;61(01):73-76

21 Tasian GE, Copelovitch L. Evaluation and medical management of kidney stones in children. J Urol 2014;192(05):1329-1336

22 Paterson R, Fernandez A, Razvi H, Sutton R. Evaluation and medical management of the kidney stone patient. Can Urol Assoc J 2010;4(06):375-379

23 Kang DE, Sur RL, Haleblian GE, Fitzsimons NJ, Borawski KM, Preminger GM. Long-term lemonade based dietary manipulation in patients with hypocitraturic nephrolithiasis. J Urol 2007;177 (04):1358-1362, discussion 1362, quiz 1591

24 Penniston KL, Nakada SY, Holmes RP, Assimos DG. Quantitative assessment of citric acid in lemon juice, lime juice, and commercially-available fruit juice products. J Endourol 2008;22(03):567-570

25 Porowski T, Kirejczyk JK, Konstantynowicz J, et al. Correspondence between $\mathrm{Ca}^{2+}$ and calciuria, citrate level and $\mathrm{pH}$ of urine in pediatric urolithiasis. Pediatr Nephrol 2013;28(07):1079-1084

26 Turudic D, Batinic D, Golubic AT, Lovric M, Milosevic D. Calcium oxalate urolithiasis in children: urinary promoters/inhibitors and role of their ratios. Eur J Pediatr 2016;175(12):1959-1965

27 Ennis JL, Asplin JR. The role of the 24-h urine collection in the management of nephrolithiasis. Int J Surg 2016;36(Pt D):633-637

28 Marra G, Taroni F, Berrettini A, Montanari E, Manzoni G, Montini G. Pediatric nephrolithiasis: a systematic approach from diagnosis to treatment. J Nephrol 2018. Doi: 10.1007/s40620-018-0487-1 